\title{
CONTROL OF CRACK LOCALIZATION AND FORMATION OF FAILURE PATH IN RC MEMBERS CONTAINING ARTIFICIAL CRACK DEVICE
}

\author{
Amorn PIMANMAS $^{1}$ and Koichi MAEKAWA ${ }^{2}$ \\ ${ }^{1}$ Member of JSCE, Ph.D., Research fellow, Dept. of Civil Eng., The University of Tokyo \\ (Hongo 7-3-1, Bunkyo-ku, Tokyo 113, Japan) \\ ${ }^{2}$ Member of JSCE, Dr. of Eng., Professor, Dept. of Civil Eng., The University of Tokyo \\ (Hongo 7-3-1, Bunkyo-ku, Tokyo 113, Japan)
}

\begin{abstract}
Excessive usage of shear reinforcement results in the reinforcement congestion, which troubles concrete work and may degrade the overall quality of reinforced concrete members. Hence, the reduction in the amount of shear reinforcement is of engineering need. Recent experiments on precracked beam have shown the crack arrest and diversion of crack paths, which lead to the substantial increase in shear capacity even without transverse bars. This idea leads to the proposal of Artificial Crack Device (ACD) to emulate pre-cracks. Experimental results have shown the capability of this device in controlling the crack propagation.
\end{abstract}

Key Words: artificial crack device, local shear anisotropy, control of crack localization, crack arrest and diversion, failure path formation

\section{INTRODUCTION}

Until now, the design of reinforced concrete (RC) members has primarily relied on using reinforcing bars to carry tension after cracking of concrete. Since reinforcing bars function to distribute external forces in the $\mathrm{RC}$ members, localization due to crack propagation can be prevented. In this regard, reinforcing bar can be viewed as a control device of crack localization. A successful use of reinforcing bars in conventional practice is given in Fig. 1. Illustrated here is the concrete beam reinforced with longitudinal main reinforcements and shear reinforcements. The purpose of main bars is to support tension with the same amount of concrete compression. Thus, the internal couple to equilibrate the external moment is formed (Fig. 2a). Here, the load bearing action can be obtained if sufficient bond between steel bar and concrete is provided. The function of shear reinforcements is to form the internal truss to support the shear stress (Fig. 2b).

If these reinforcing bars are sufficiently arranged in $\mathrm{RC}$ members, the cracks formed, whether of flexural or of diagonal shear, can be well distributed in a smeared area where external forces can be effectively transferred. Through the use of reinforcing bars, the localization of cracks can be relieved. However, the excessive use of shear reinforcement brings about the congestion of reinforcing bars. This causes the difficulty in

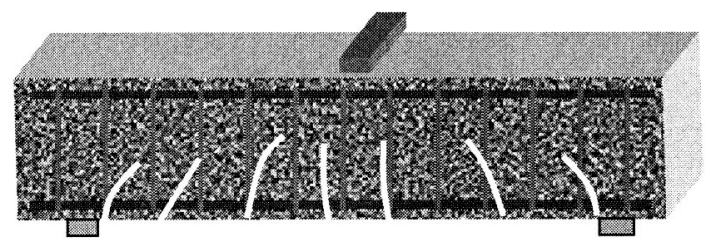

Fig. 1 Convention RC design
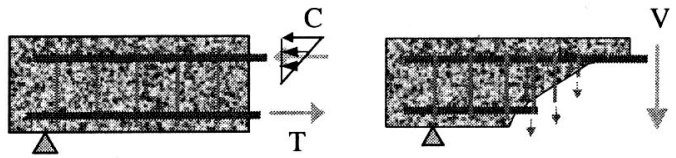

(a) Flexural action (C-T couple)

(b) Shear action (Truss theory)

Fig.2 Concrete and reinforcements in resisting external actions

concrete casting and compaction and may result in poor RC quality. The long-term durability problem may become serious.

Moreover, in practice, providing main reinforcing bars for flexure can be easily accomplished. However, this is not necessarily true for shear reinforcements. In some structures like RC slab, foundation, etc., the fabrication of transverse bars is relatively laborious, costly and time consuming. Therefore, usual practice designates the concrete to entirely resist shear. For this kind of structures, minimal usage or even none of shear reinforcement is generally accepted. 
The conventional RC design approach views reinforcing bars as the tensile resistant mechanism rather than a means to control the crack localization. In this paper, control of crack localization is proposed as a supplement to the conventional design approach. According to the new concept, engineers should be able to manage the crack propagation behavior inside RC members. They should specify where, when and how the cracks will be initiated and propagated.

The capability to control the crack localization may lead to the effective usage of reinforcing bars. The objective of this paper is (1) to find the means to increase the concrete shear capacity other than shear reinforcement and (2) to control the crack propagation behavior of RC members. This may lead to a new perspective towards the shear design method.

\section{SHEAR TEST OF PRE-CRACKED BEAM}

Reinforcing bars can be used as a means to control the crack localization. However, the control of crack localization is not limited to only the usage of reinforcing bars. Recent experiments on precracked beam conducted by the authors ${ }^{1)}$ showed another possibility for this purpose. In Fig.3, the experimental program on the shear test of precracked beam is shown. Pre-cracks penetrating the entire sections were introduced by means of reversed flexural loading (Fig.3a). This required two steps of flexural loading. After the first flexure, the beam was rotated through $180^{\circ}$, then the second flexure was applied. To apply shear loading, supports were moved towards beam mid-span such that shear span to effective depth ratio was 2.41 (Fig.3b). Tested compressive strength of concrete was $26.5 \mathrm{MPa}$. Tested yield strength of main bars was $338.4 \mathrm{MPa}$.

Fig.4 shows experimental results. Typical loaddisplacement relation of the pre-cracked beam is shown in Fig.4a. It is noted that the pre-cracked beam can reach significantly higher loading capacity than the non pre-cracked one. Up to $50 \%$ increase in loading capacity till yielding of main bars was observed. Failure crack patterns of the non precracked and the pre-cracked beams are shown respectively in Fig.4b and Fig.4c. Substantial difference between these two cases is clearly identified. In the pre-cracked beam, numerous discontinuous diagonal cracks are created whereas only one single diagonal crack is formed in the non pre-cracked beam. The difference in failure behavior

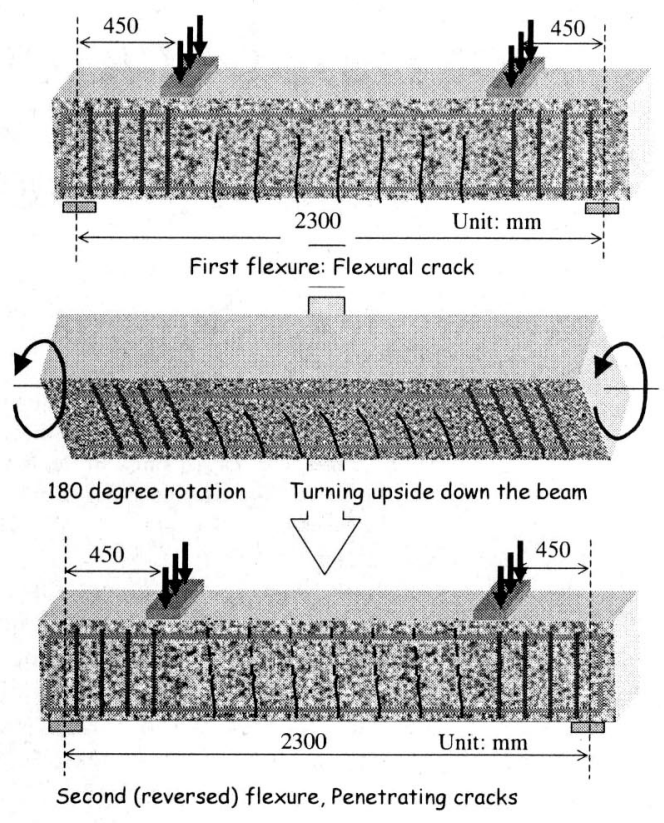

(a) First step - reversed flexural loading test

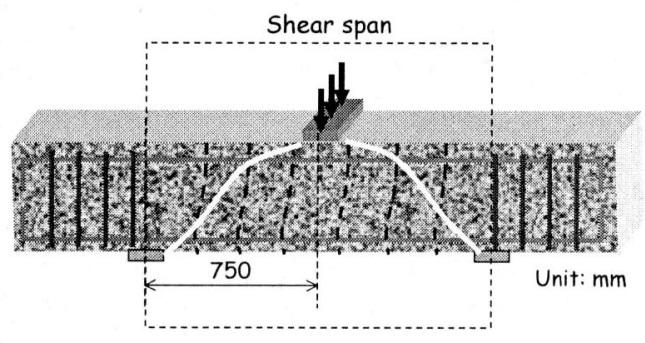

(b) Second step -shear test

Fig. 3 Outline of shear test of pre-cracked beam ${ }^{1)}$

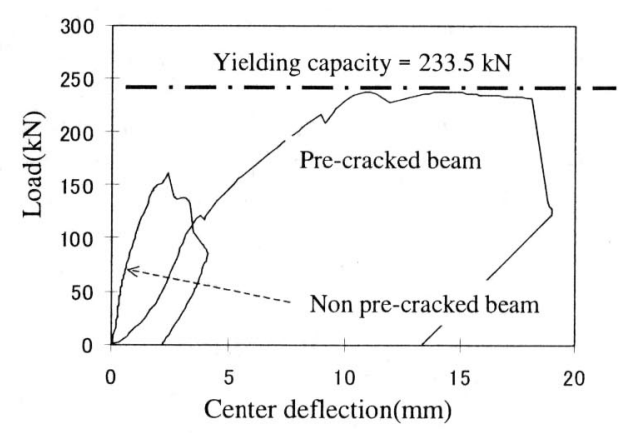

(a) Load-displacement relation of pre-cracked and non pre-cracked beams

Fig.4 Experimental results of shear test on pre-cracked beam ${ }^{1)}$

is explained by the mechanism of crack arrest and diversion in the next section. 


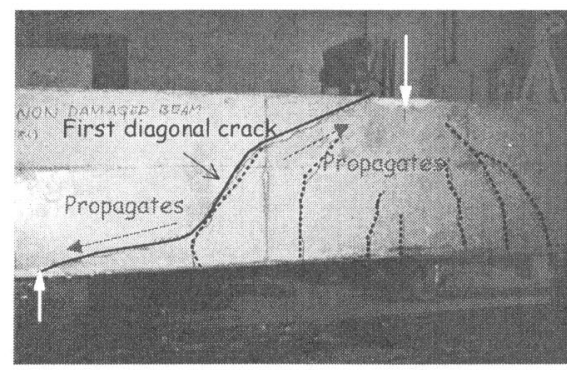

(b) Failure crack pattern of non pre-cracked beam

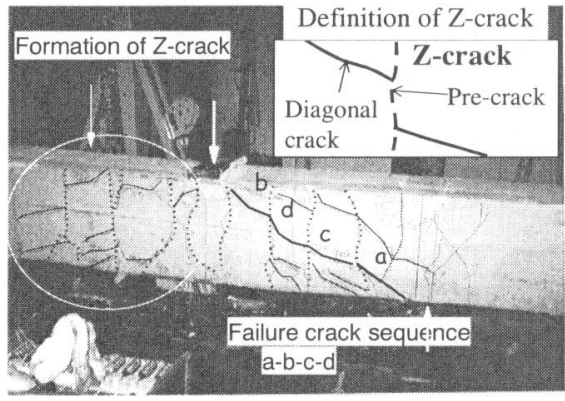

(c) Failure crack pattern of pre-cracked beam

Fig.4 Experimental results of shear test on pre-cracked beam ${ }^{1)}$

\section{CRACK LOCALIZATION AND MECHANISM OF CRACK ARREST AND DIVERSION}

The failure behavior is different between non pre-cracked and pre-cracked beam. In the non precracked beam, only a single diagonal crack with a sharp localization leads to an immediately failure. On the contrary, in the pre-cracked beam, the diagonal crack cannot continuously propagate due to the crack arrest and diversion mechanism ${ }^{1)}$. At the pre-crack plane, only low stresses can be transferred, which are not enough for further cracking (Fig.5), thus, the propagation of diagonal crack is terminated there.

As a result, shear failure is delayed and a substantial increase in shear capacity of the precracked beam can be obtained. The beam typically forms the failure path by independently creating necessary diagonal cracks along the path connecting loading point to the support (Fig.6). The formation of failure path is complete when cracks along the path combine together into one single crack. This brings the ultimate failure to the beam. In precracked beam with vertical pre-cracks, several diagonal cracks are created. This results in higher deformation, less stiffness and higher energy
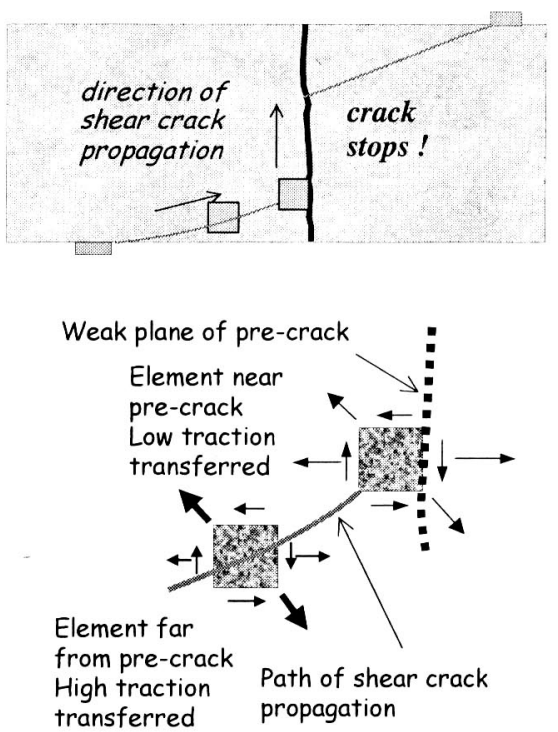

Fig. 5 Mechanism of crack arrest and diversion ${ }^{1)}$
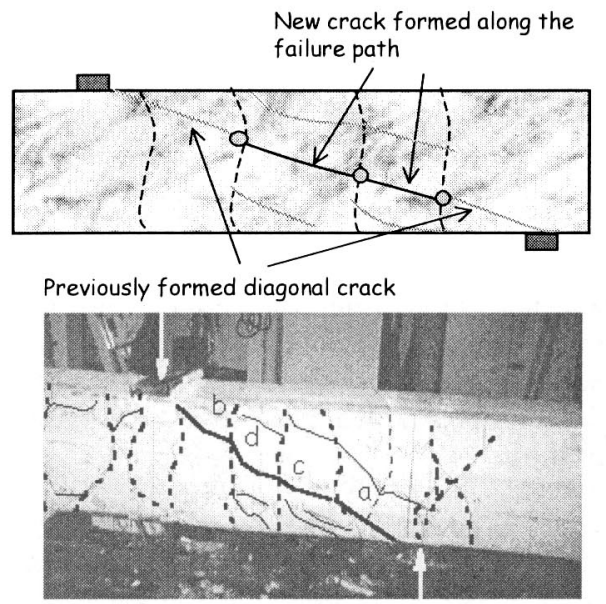

Fig. 6 Failure path formation in pre-cracked beam ${ }^{1)}$

consumption compared to those of the non precracked beam. Cracks formed in pre-cracked beam have Z-shape pattern due to the mutual contribution of the pre-crack and the diagonal crack. Properties of pre-cracks affect the geometry of the formed Zcrack $^{1)}$, which in turn affects the loading capacity, failure characteristics and load-displacement relation.

Some important properties of pre-cracks include inclination, width, roughness, location and spacing. The effect of the width of the pre-crack is illustrated in Fig.7. As shown in the figure, the smaller precrack indicates less contribution of pre-crack deformation mode, thus the formed Z-crack has the shape as shown in Fig.7a where the pre-crack 

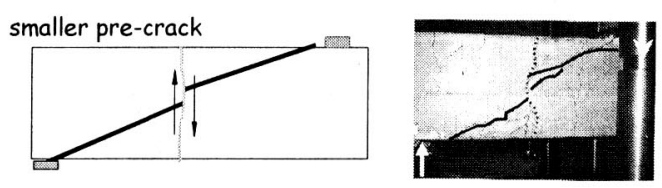

(a) Z-crack in which diagonal crack dominates
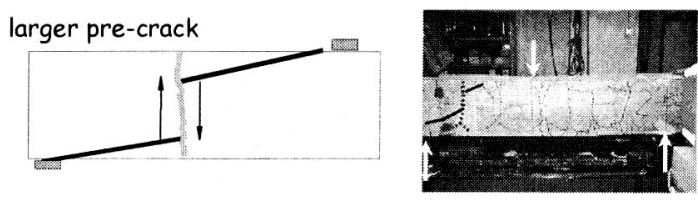

(b) Z-crack in which pre-crack dominates

Fig.7 Geometry of Z-crack and width of pre-crack ${ }^{1)}$

occupies relatively smaller portion. On the contrary, when the vertical pre-crack is large, the formed Zcrack has the shape as shown in Fig.7b, which reflects the significance of shear slip along precrack interface. It is supposed that the shear transfer along pre-crack interface affects the principal stress developed in the concrete element near pre-cracks ${ }^{1)}$. Finite element analysis was conducted to simulate the shear behavior of pre-cracked beam ${ }^{2), 3)}$. It is shown that the fixed crack approach, which explicitly considers shear transfer due to aggregate interlock, can capture crack paths consistently for both small and large pre-crack widths.

It is seen that the crack arrest and diversion phenomenon shows another possible method of controlling the crack localization ${ }^{1)}$. Based upon this experimental result, the concept of crack arrest and diversion is applied as a means to control the crack localization.

\section{FAILURE PROCESS IN ORDINARY SLENDER BEAM}

Failure process in an ordinary slender beam is reviewed in this section. It is noted that the knowledge of failure path is important for the effective crack control. The shear failure process in an ordinary slender beam follows a certain sequence as shown in Fig.8. The first step is the arrival of the first diagonal crack, crack 2, around the web portion at the center of shear span. This diagonal crack is usually observed just above the nearby flexural crack (crack 1 in Fig.8).

The arrival of crack 2 is the first step in the shear failure process. The second step is the propagation of this crack towards the loading point and backwards the support. This results in cracks 3 and

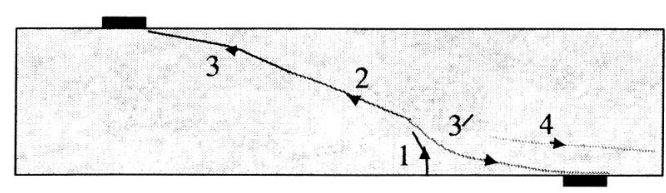

Crack 1: Flexural crack

Crack 2: Advent of first diagonal crack

Crack 3,3': Propagation of crack 2

Crack 4: Sudden energy release from the beam

Fig. 8 Conventional failure path formation in slender beam
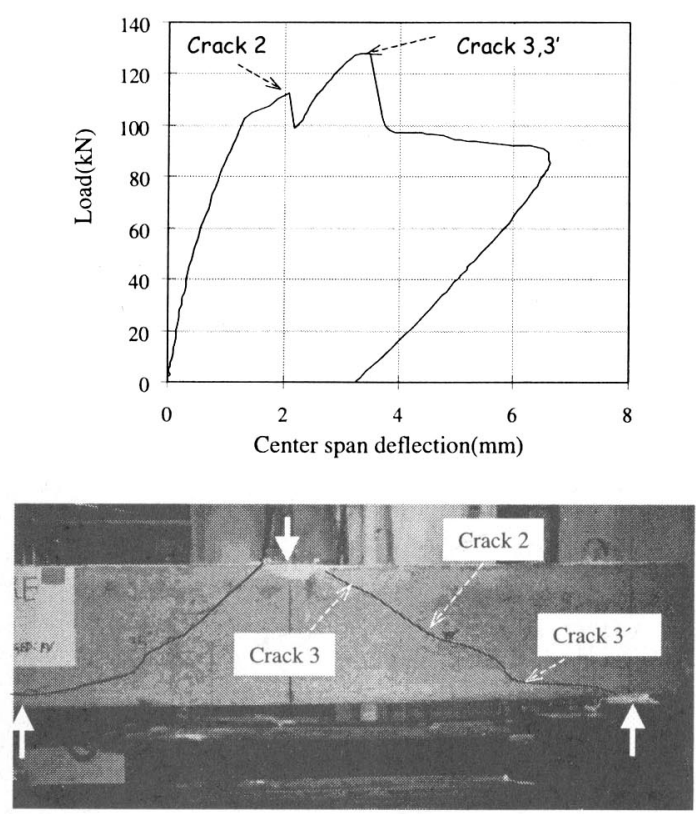

Fig. 9 Differentiation between first stage crack initiation (crack 2) and second stage crack propagation (crack 3')

3' (Fig.8), respectively. Once these cracks have been formed, the failure is immediate and accompanied by the drop in loading capacity.

Normally, the instant between the first step of crack initiation and the second step of critical propagation is nearly the same. In fact, the experiment shows that only the arrival of crack 2 does not immediately fail the beam yet. It is the occurrence of crack $3^{\prime}$ that truly brings failure to the beam. Thus, a slight increase in loading capacity after the arrival of crack 2 may be observed (Fig.9). This identifies that the shear failure process in a slender beam must consist of two different steps. In some beams, for example, the one shown in Fig.10, the step 1-initiation (crack 2) and step 2-propagation (crack 3,3') into the failure crack occur virtually at the same instant, thus the increase in loading capacity is not observed. 

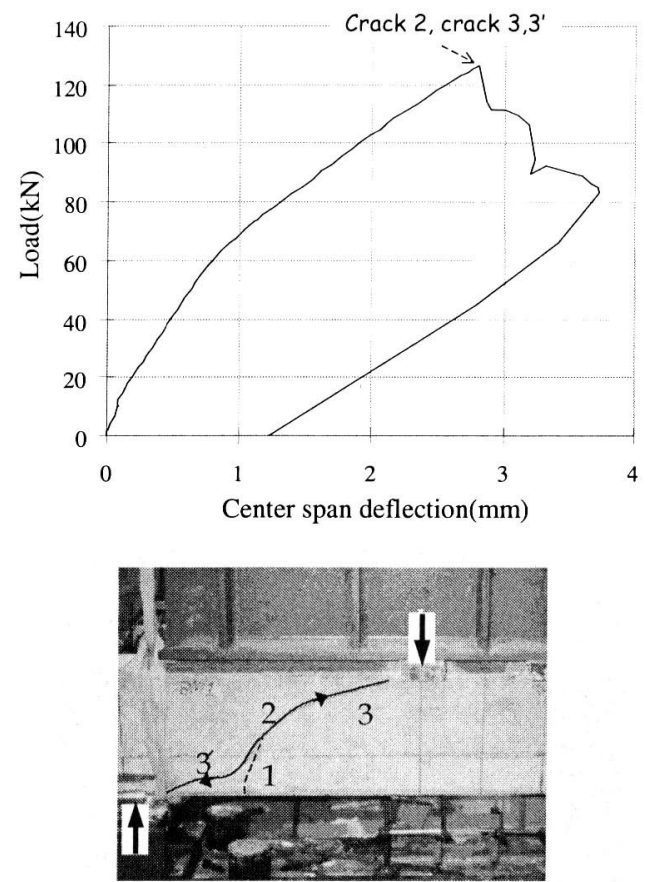

Fig. 10 Initiation and propagation of diagonal crack are at the same instant

In addition, in other beams, a sudden formation of crack 4 (Fig.8) is sometimes observed with the explosive sound and the corresponding sharp drop in the loading capacity. Crack 4 is normally nearly horizontal and penetrating through the beam end. It is noted that the crack can take place even if no stresses can be transferred through that location. The sudden formation of crack 4 causes the abrupt release of energy out of the beam corresponding to the sharp drop in the applied loading.

\section{POST-DIAGONAL CRACK HARDENING/SOFTENING BEHAVIOR}

In an ordinary slender beam loaded in shear, the arrival of the first diagonal crack at the web zone generally indicates the failure. The post-diagonal crack behavior is usually characterized by the abrupt softening. However, there can be a little increase in loading capacity after the first diagonal takes place. As described in the previous section, the failure is defined not at the initiation, but at the propagation of diagonal crack. Thus there can be a slight postdiagonal crack-hardening in the ordinary beam (Fig.11). However, this can be ignored since the propagation of the diagonal crack usually occurs very soon after the first diagonal crack appears.

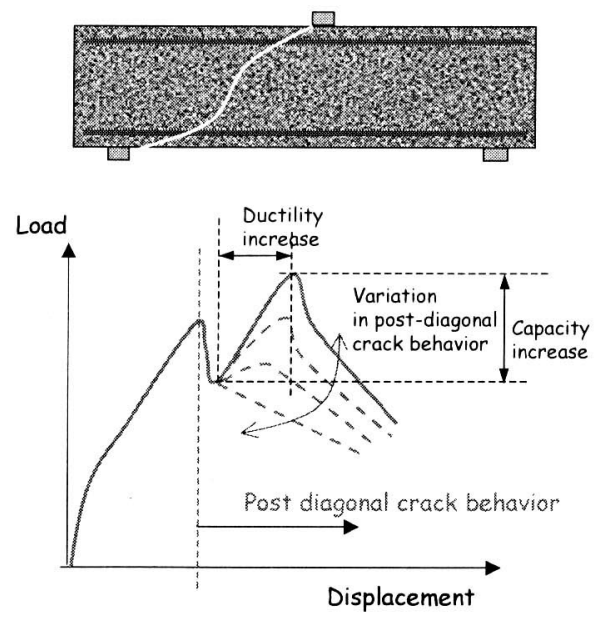

Fig.11 Post-diagonal crack behavior in a non pre-cracked ordinary slender beam
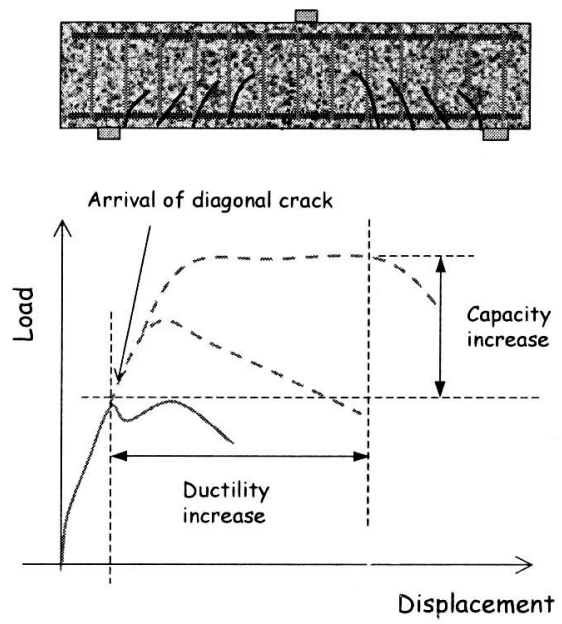

Fig. 12 Post-diagonal crack behavior in beam with shear reinforcement
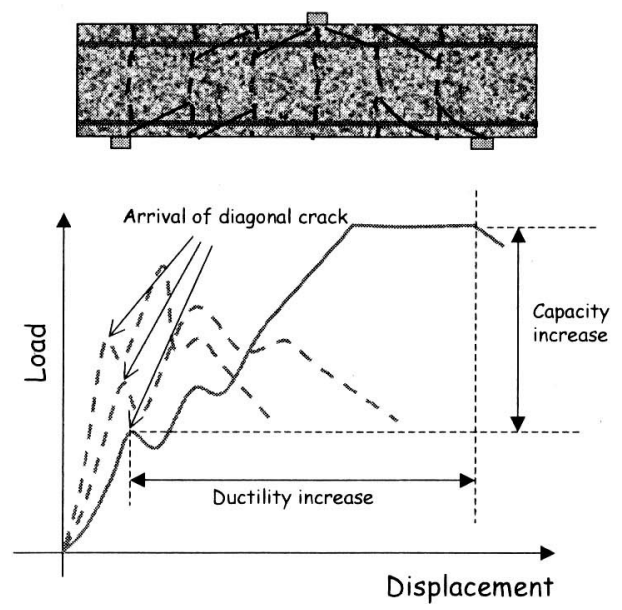

Fig.13 Post-diagonal crack behavior in pre-cracked beam 

(1) Specification of
crack location

(2) Stoppage of crack propagation

(3) Diversion of crack propagation direction
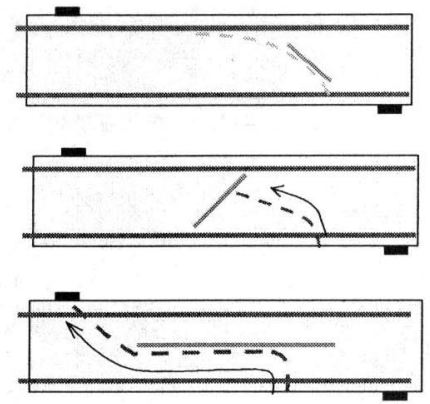

Fig. 14 Basic controls of crack localization

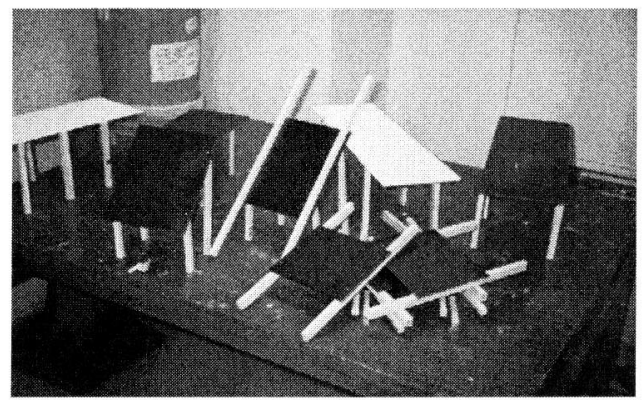

Fig.15 Artificial Crack Device (ACD)

On the other hand, there can exist significant post-diagonal crack-hardening in pre-cracked beams and beams reinforced with shear reinforcements. However, the mechanisms of post-diagonal crackhardening between the pre-cracked beam and the beam with shear reinforcements are quite different.

In the beam with shear reinforcement, a truss mechanism is formed to resist a shear force (Fig.12). The post-diagonal crack-hardening depends on the compression of concrete and tension of main and shear reinforcements. In contrast, the post-diagonal crack-hardening in pre-cracked beams is due to crack arrest and diversion mechanism ${ }^{1)}$ (Fig.13).

\section{BASICS OF CRACK CONTROL AND ARTIFICIAL CRACK DEVICE (ACD)}

Due to the phenomenon of crack arrest and diversion ${ }^{1)}$, another way in controlling the crack localization has been developed. The control of crack localization needs not be restricted to the use of reinforcing bars only. Basic crack control includes (1) determination of crack location, (2) diversion of crack propagation and (3) arrest of crack propagation as shown in Fig.14. The main objective of these controls is to avoid the fatal construction of continuous failure path.
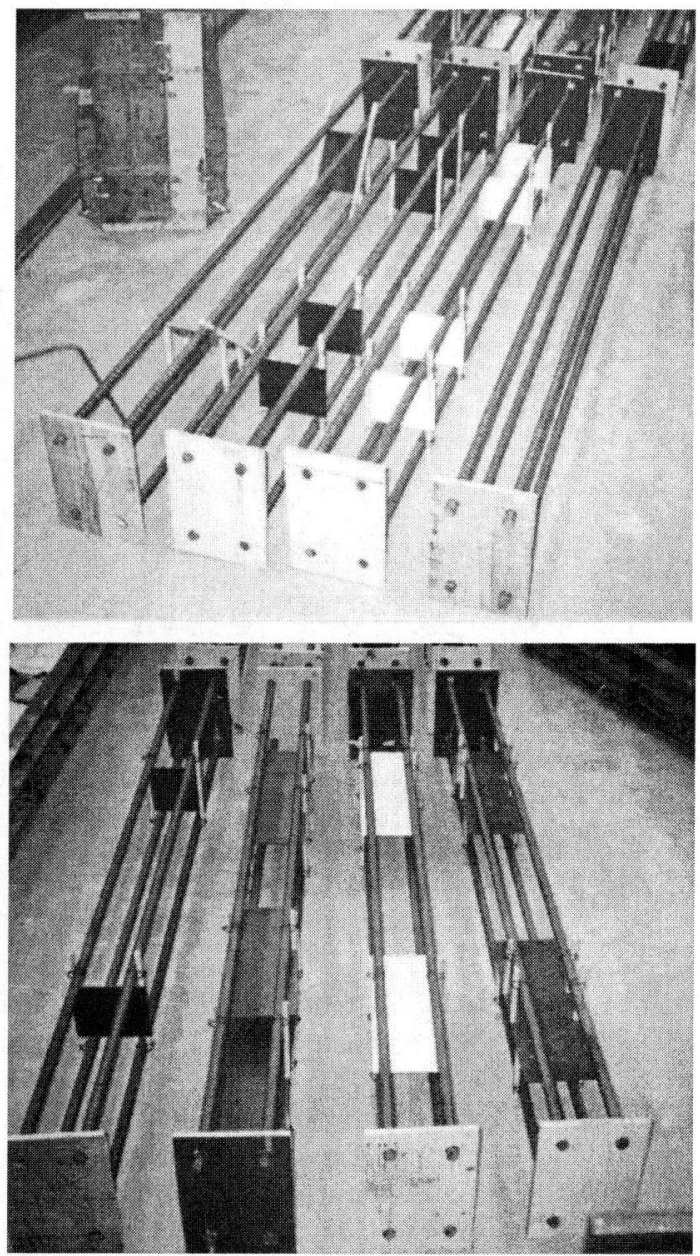

Fig.16 Arrangement of ACD and reinforcing bars

There exists the fundamental difference between the conventional control by reinforcing bars and the proposed control. In the conventional control, cracks are necessary for reinforcement to work. But in the proposed control, crack must be arrested as much as possible so as to obstruct the formation of the failure path.

To show the feasibility of the above concept of crack control, a device called Artificial Crack Device (ACD) is developed (Fig.15) which emulates the pre-crack. ACD is fabricated from steel or plastic plate, which has smooth surface and low stress transfer ability. The device is embedded in formwork before concrete casting and forms a part of the concrete members. Fig.16 shows the reinforcement and ACD arrangement. As the first proposal, ACD is designed to be embedded inside $\mathrm{RC}$ member without penetrating across the entire section as pre-cracks. Thus large shear slip and low shear transfer takes place locally at ACD interface. 


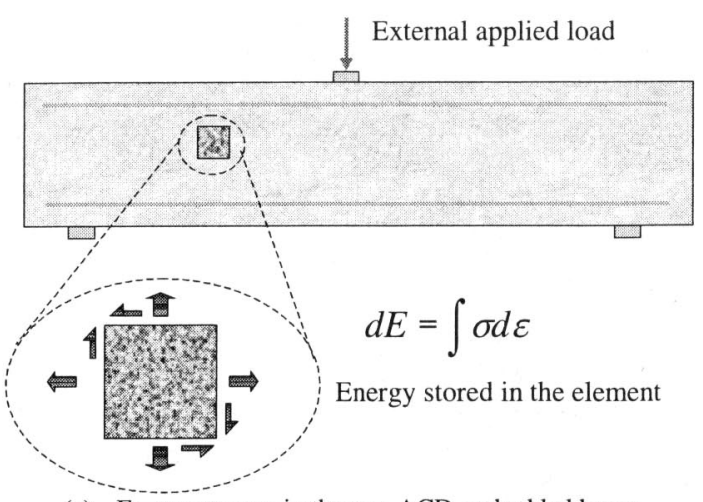

(a) Energy storage in the non ACD-embedded beam

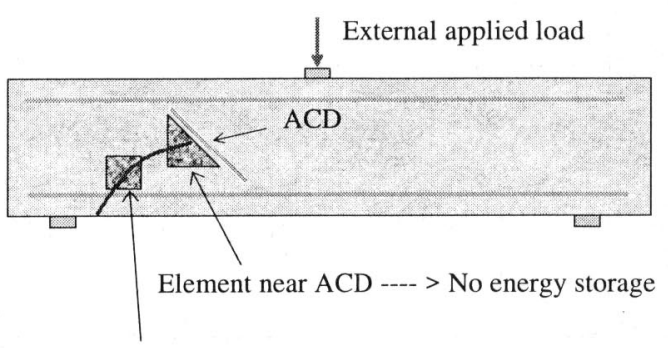

Element far from ACD -------> Available energy storage

(b) Energy shortage in concrete element near ACD in the ACD-embedded beam

Fig.17 Energy storage in the beam

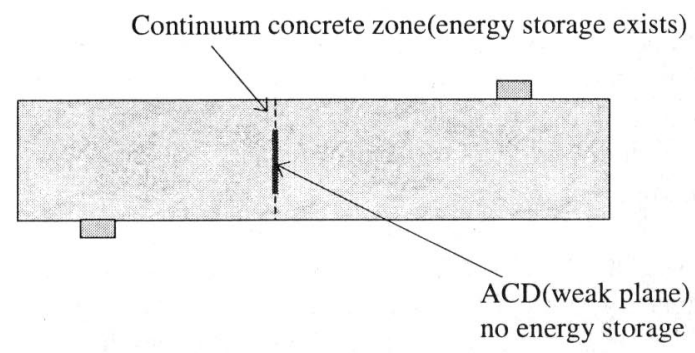

Fig.18 Mixed deformational characteristics at the ACD location

Because of this fact, a certain difference may be expected between ACD and the pre-crack, which is discussed later.

Both steel and plastic materials are used for ACD. Plastic material may be considered beneficial in terms of durability and easiness in manipulation. From the mechanical point of view, the strength of ACD is thought to have no significant influence, since the crack arrest is caused by low stress transfer ability of the ACD interface. Basically, it is supposed that the interface property of steel and plastic ACD would be the same. However, stiffnesses of plastic and steel are different which may affect the interaction with concrete. This is

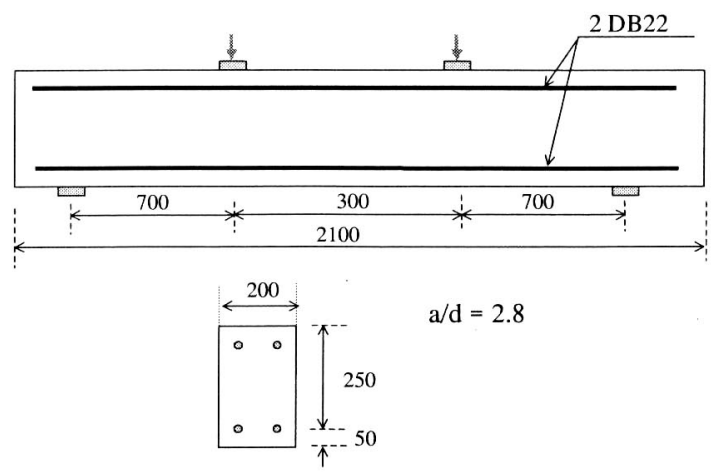

Fig.19 General test set-up of ACD-embedded beam (unit:mm)

studied in the experiment.

It should be further noted that ACD is a weak plane inside the member. Thus ACD itself may bring failure to the $\mathrm{RC}$ member. This point is also clarified in the experiment.

For localization to take place successfully, energy consumption is required. In an ordinary beam, this energy is obtained from the strain energy (Fig.17a). But if ACD is placed inside the member, concrete adjacent to ACD is less stressed and strained as a result of low stress transfer at the ACD interface. This results in smaller energy stored in these concrete elements (Fig.17b). Thus, when the crack propagates into the concrete near $\mathrm{ACD}$, the propagation must be terminated since no energy is to be consumed.

\section{EXPERIMENTAL PROGRAM}

\section{(1) Experimental program}

The placement of ACD to obtain the most efficiency in arresting and diverting the crack propagation is not known. As noted, ACD is different from the pre-crack in the previous experiment ${ }^{1)}$ in that it does not penetrate the entire section. Therefore at the location of ACD, there exist both concrete part and ACD part (Fig.18). According to fracture mechanics, energy could be fully consumed by concrete part while not fully consumed at the ACD interface. Therefore, the crack may penetrate through the surrounding concrete but not through the ACD interface.

To investigate the localization control, an experimental program was carried out. Eight beams with ACD inside in different locations and inclinations (Fig.20) were tested in shear. The loading set up is shown in Fig.19. The shear span to effective depth ratio is 2.8. Reinforcement ratio of main bars is $1.548 \%$. Tested compressive strength 


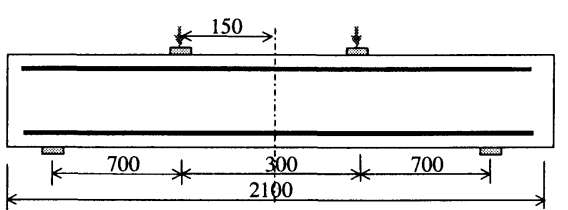

(a) Beam 1: Reference beam

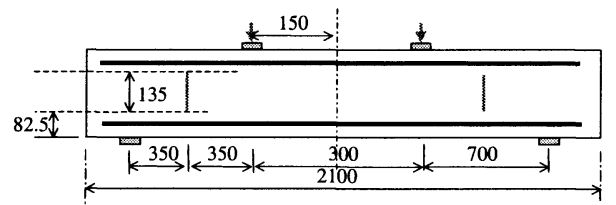

(b) Beam 2: Vertical steel ACD

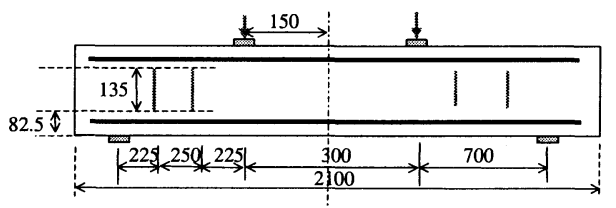

(c) Beam 3: Vertical steel ACD

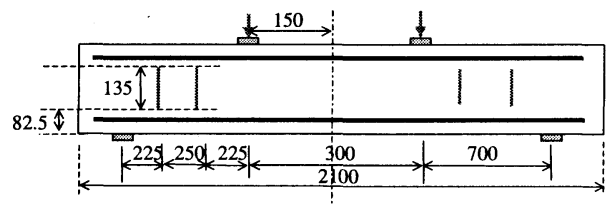

(d) Beam 4: Vertical plastic ACD

Fig.20 Layout of ACD-embedded beam (1) (unit:mm)

of concrete is $31.4 \mathrm{MPa}$. Tested yield strength of main reinforcement is $397.3 \mathrm{MPa}$. No shear reinforcements are arranged in the test beams.

Beam 1 is the reference beam. In beams 2, 3 and 4 , vertical ACD is embedded. Beam 2 is equipped with a vertical steel $A C D$ at the center of each shear span. In beam 3, two vertical steel ACDs are placed in each shear span. Beam 4 has the same ACD configuration as in beam 3 but it uses plastic ACDs instead. In beam 5, inclined ACD is embedded in the near orthogonal direction to the direction of the crack propagation. Beam 6 and beam 7 use one horizontal ACD placed along the centroidal axis. Beam 6 uses steel ACD while beam 7 uses plastic one. In beam 8, two horizontal steel ACDs are placed in each shear span. It is noted that the arrangement of the ACD is various in order to obtain the diversity in experimental results.

\section{(2) Experimental results and discussion}

\section{a) Beam 1: Non ACD-embedded beam}

Beam 1 is the reference beam with no ACD inside. Load-displacement relationship is shown in Fig.21a. The failure crack pattern is shown in Fig.21b. The first diagonal crack is observed around

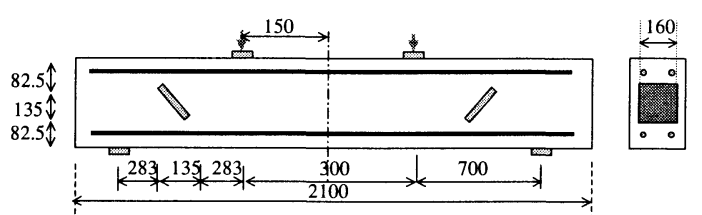

(e) Beam 5

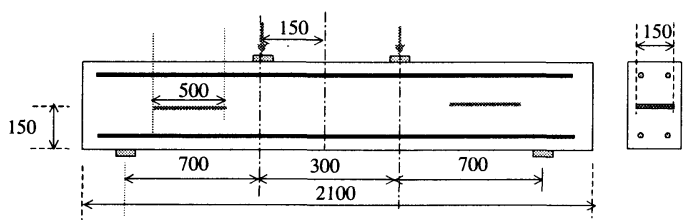

(f) Beam 6: Horizontal steel ACD

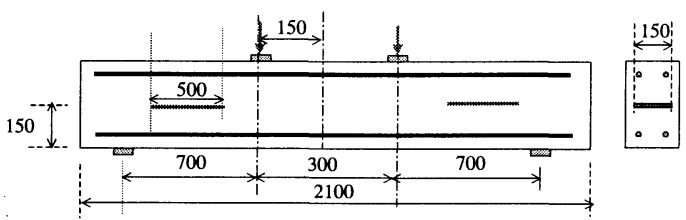

(g) Beam 7: Horizontal plastic ACD

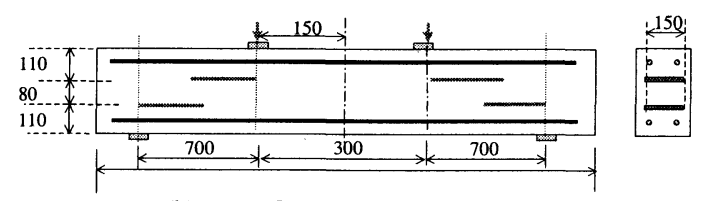

(h) Beam 8: Horizontal steel ACD

Fig.20 Layout of ACD-embedded beam (2) (unit:mm)

the web portion, propagates towards the loading point and the support and immediately fails the beam. The loading capacity is $126.5 \mathrm{kN}$ although Okamura-Higai equation ${ }^{4)}$ predicts $128.7 \mathrm{kN}$.

\section{b) Beam 2}

The load-displacement relationship of beam 2 in Fig.22a does not show the increase in loading capacity compared with the reference beam. In this case, ACD does not arrest the crack propagation. On the contrary, ACD itself initiates the first crack. However, from the crack pattern (Fig.22c), it is seen that no diagonal cracks propagate through ACD either. The stress concentration in diagonal direction is relieved due to low stress transfer at ACD plane. Thus, in this beam, ACD does neither arrest the crack nor allow the crack to pass through.

The failure process is shown in Fig.22b. Crack 1 at the ACD interface occurs first and extends into diagonal crack 2 towards the loading point. Crack 3 is also extended from crack 1 in the direction of support. The cracks 1,2 and 3 then form the failure path. From the crack pattern, it can be seen that the crack can propagate across the concrete part adjacent to ACD and can form the failure path successfully. 


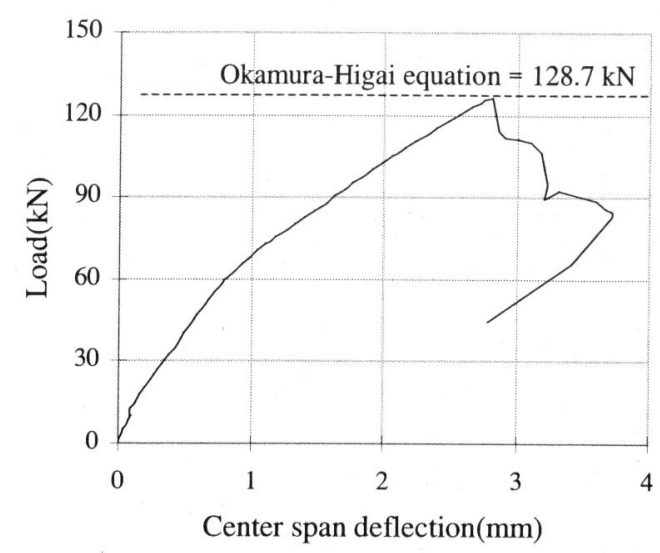

(a) Load-displacement relationship of beam 1

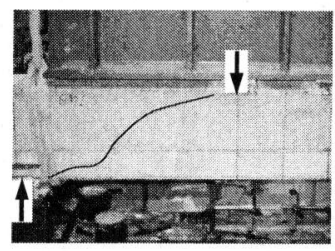

(b) Failure crack pattern

Fig.21 Experimental result of beam 1

This experiment shows that ACD is the weak plane in the member and can prematurely initiate the crack itself. This has a benefit and a drawback. The benefit is that ACD can be used to specify the crack location. This may be useful for avoiding cracks at some critical locations by specifying other locations of crack occurrence where the maintenance or reinforcement can be done more easily. As the drawback, since ACD can cause the crack easily, this way of placing ACD is not recommended for arresting the crack propagation.

\section{c) Beams 3 and 4}

In beams 3 and 4, two vertical ACDs are placed in each side of the beams. Steel ACD is used in beam 3 while plastic one is used in beam 4 . In both beams, initial cracks similar to that in beam 2 are observed at the ACD interface (Fig.23).

In beam 3 , the failure process is essentially the same as in beam 2. The failure crack is formed at the right $\mathrm{ACD}$ in the right side of the beam (Fig.24a) and propagates diagonally towards the loading point and backwards the support. When the propagation finishes, the beam fails. In this case, ACD does not arrest any crack propagation, as crack propagation circumvents ACD. The loading capacity (Fig.24b) is slightly decreased due to the premature occurrence of the crack at the ACD interface.

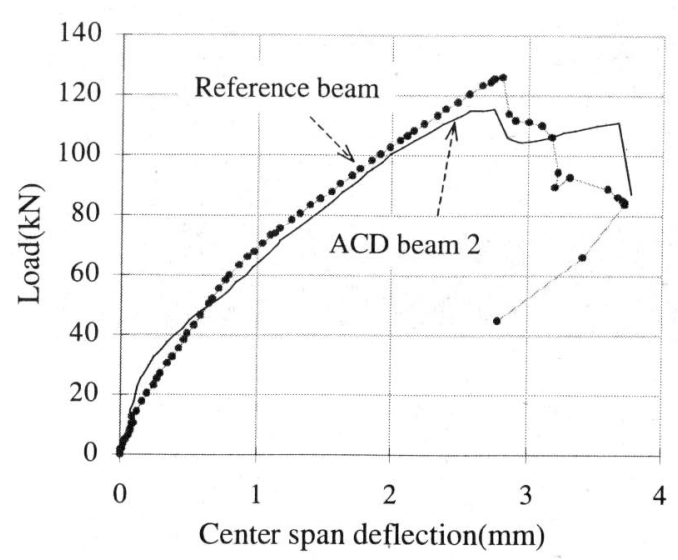

(a) Load-displacement relationship

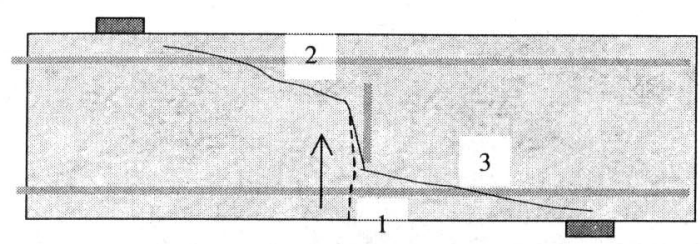

Sequence of failure formation: $1-2-3$

(b) Sequence of failure crack

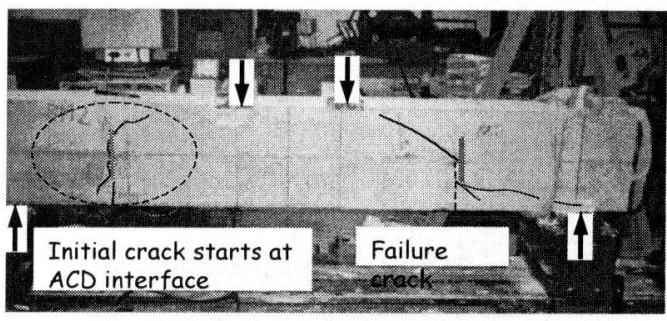

(c) Experimental crack pattern

Fig.22 Experimental result of beam 2

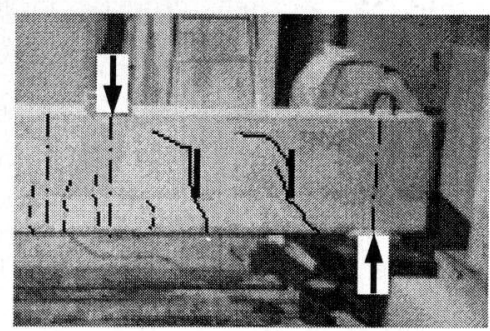

Fig.23 Initial cracks developed at the ACD interfaces

The failure process in beam 4 is shown in Fig.25a. The first diagonal crack 1, occurs and propagates into crack 2 and crack 3 in the direction of the loading point and the support, respectively. The failure path is formed without any obstruction from ACD. Load-displacement relationship is 

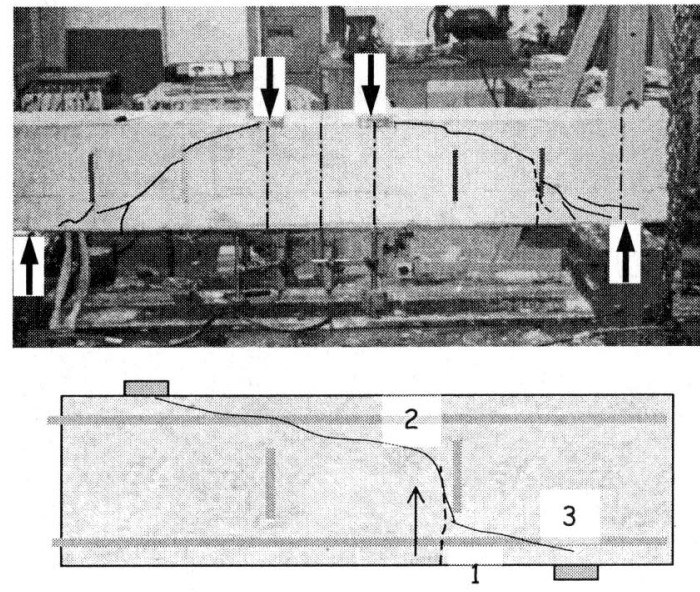

Sequence of failure formation: $1-2-3$

(a) Failure crack and failure process of beam 3

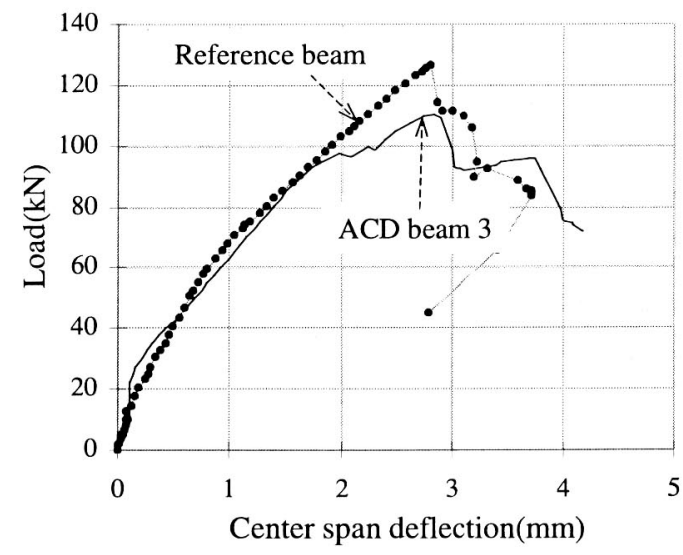

(b) Load-displacement relationship of beam 3

Fig.24 Experimental result of beam 3

shown in Fig.25b. A slight decrease in loading capacity is seen.

\section{d) Beam 5}

In beam 5, a steel ACD is arranged in the direction normal to the crack propagation. Loading capacity significantly increases up to $56 \%$, from $126.5 \mathrm{kN}$ of reference beam to $197.3 \mathrm{kN}$ (Fig.26b). The failure process is described in Fig.26a. Firstly, a flexural crack, crack 1 , is observed and turns into a diagonal crack. Then, diagonal crack 2 is developed independently but does not immediately propagate backwards to the support. This is the main difference from the behavior of diagonal crack in the reference beam where the diagonal crack can propagate easily while the diagonal crack in beam 5 is arrested by ACD. Thus, the failure path is not suddenly formed and loading capacity is greatly increased. The failure of beam 5 is caused by the
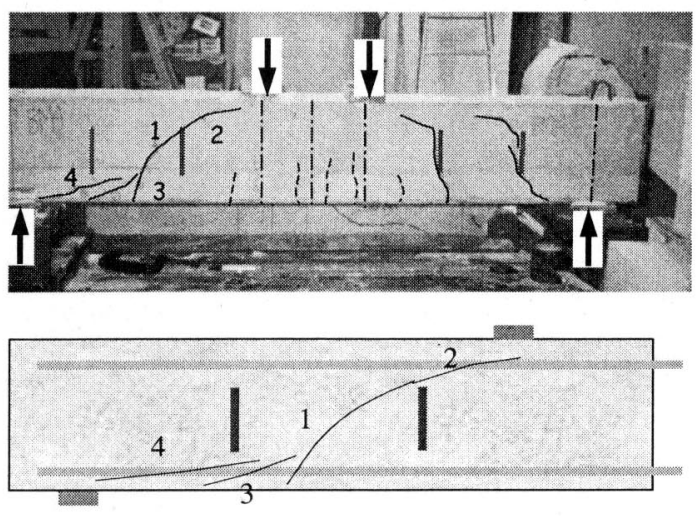

Sequence of failure formation: $1-2-3-4$

(a) Failure crack and failure process of beam 4

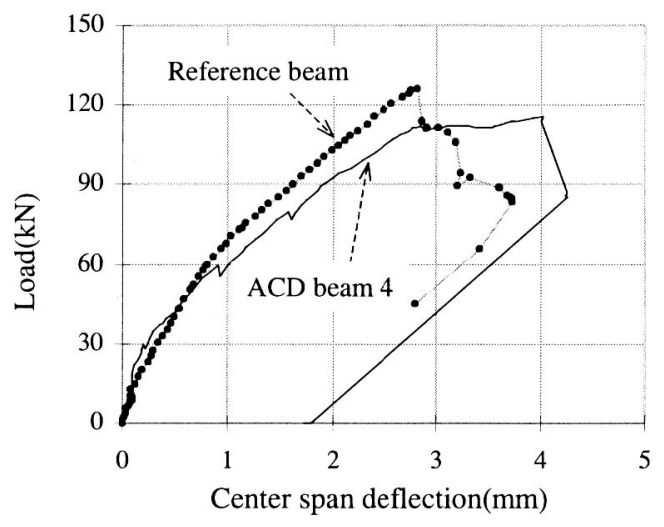

(b) Load-displacement relationship

Fig.25 Experimental result of beam 4

independent development of crack 3, which combines with crack 2 and results in the successful failure path.

In this case, it is seen that ACD can effectively arrest the crack propagation. Moreover, the arrangement of $\mathrm{ACD}$ in this inclination does not induce premature interface crack since the ACD is subjected to compression under shear loading. Since no premature crack takes place, stiffness remains the same as compared with the reference beam (Fig.26b). In the right side of the beam, the diagonal crack is seen to avoid the ACD by diverting its propagation direction (Fig.26c).

\section{e) Beam 6}

In beam 6, a horizontal steel ACD is arranged at the centroidal axis of the beam. The crack diversion is clearly observed as shown in Fig.27. The failure process is described in Fig.27a. Firstly, flexural crack, crack 1 occurs but cannot evolve into the diagonal crack due to the existence of ACD. 


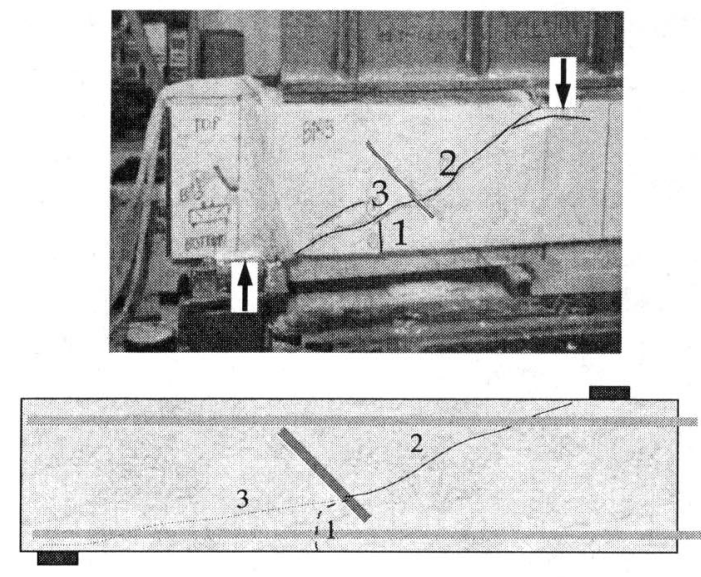

Sequence of failure formation: $1-2-3$

(a) Failure crack and failure process

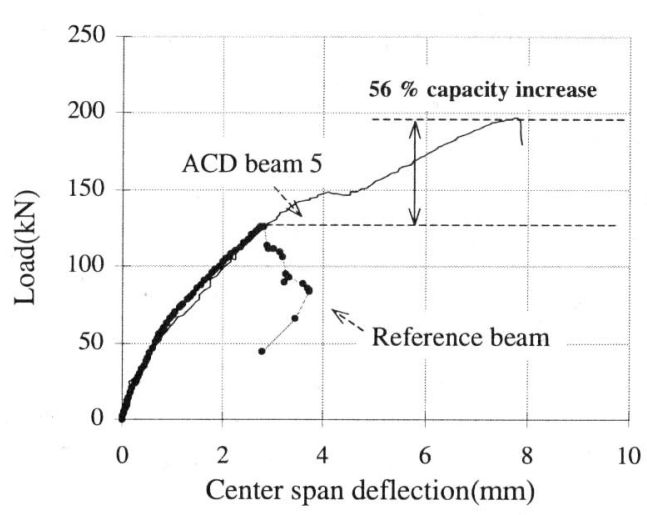

(b) Load-displacement relationship

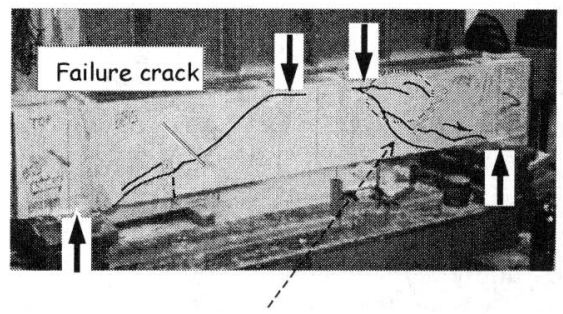

This crack tries to avoid $A C D$ by diverting its direction of propagation

(c) Attempt of diagonal crack to avoid ACD

Fig.26 Experimental result of beam 5

Instead, horizontal crack 2 takes place when crack 1 reaches the ACD plane. Then, horizontal crack 2 propagates into diagonal crack 3 towards the loading point. The resulting crack path $1-2-3$ is equivalent to the crack 1-2-3 in the reference beam as shown in Fig.27b. In beam 6, crack 2, instead of

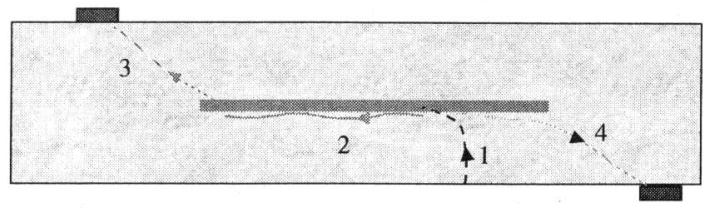

Failure crack process crack sequence: 1 - 2 - 3-4

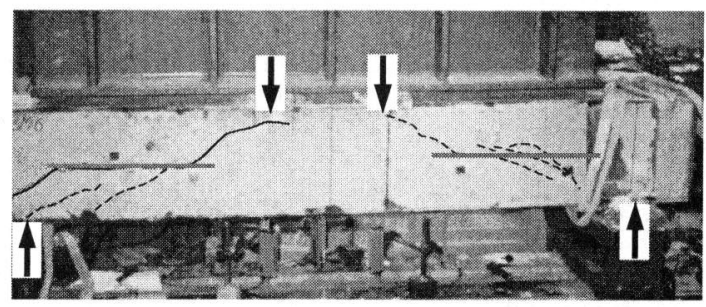

(a) Crack formation process

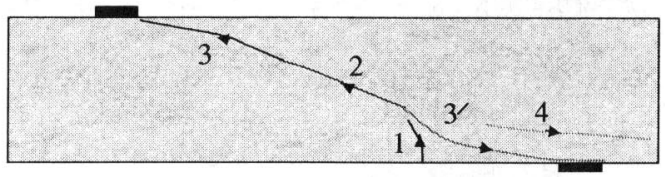

(b) Conventional failure process (repeat Fig.8)

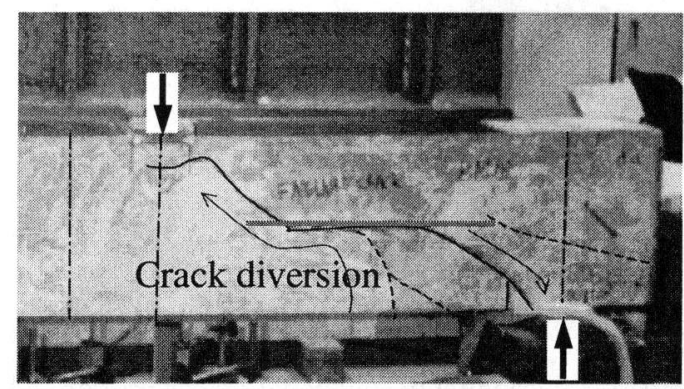

(c) Close-up of failure crack

Fig.27 Experimental result of beam 6

being diagonal, becomes horizontal by virtue of ACD. At the ACD interface, small stresses can be transferred, therefore, any imposed shear deformation must be localized into horizontal shear slip. This explains the reason why the diagonal crack cannot form at the ACD interface. The failure in beam 6 is finalized by crack 4 (Fig.27a), which is the propagation of the interface crack backwards the support.

Load-displacement relationship is shown in Fig.27d. As shown, only $11 \%$ increase in loading capacity can be obtained. The noticeable decrease in stiffness at the load around $87 \mathrm{kN}$ indicates the arrival of crack 2 , which is quite earlier compared with that of the conventional diagonal crack in the reference beam. 


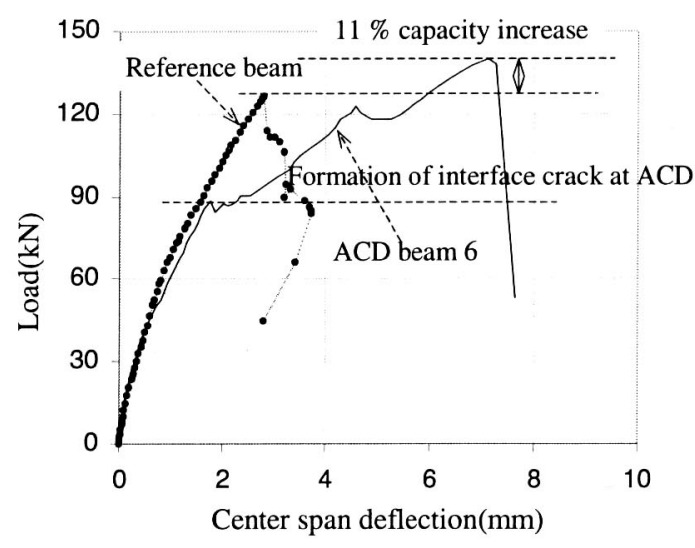

(d) Load-displacement relationship

Fig.27 Experimental result of beam 6 (Continued)

Experimental crack pattern (Fig.27c) shows that the diagonal crack cannot propagate diagonally across the ACD, but the increase in loading capacity is not significant. This is due to the fact that $\mathrm{ACD}$ is the weak plane. The horizontal placement of ACD in this beam provides two contradictory effects on the crack propagation. Diversion of crack path is thought to increase the capacity. But the arrival of crack 2 is relatively premature which causes early failure. In this beam, crack 2 itself forms a part of the failure path.

\section{f) Beam 7}

The arrangement of ACD in beam 7 is the same as beam 6 except that plastic ACD is used. Experimental crack pattern is shown in Fig.28a. It is seen that a single diagonal crack cannot successfully propagate, but is arrested by ACD. Instead, numerous discontinuous diagonal cracks are formed on one face of the beam, particularly beneath the $\mathrm{ACD}$ as shown in the figure. These diagonal cracks, when arrived at the ACD plane, redirect their propagation into along the ACD interface.

Due to discontinuity of crack propagation, the localization is relieved and the capacity is increased. Comparison of load-displacement relationship between beam 7 and reference beam (Fig.28b) shows $40.2 \mathrm{kN}$ increase in the loading capacity, which is equivalent to $33 \%$ capacity improvement. It is noted that plastic ACD is used in beam 7 but it shows higher capacity than beam 6 in which steel ACD is embedded. It is supposed that the interface property between steel and plastic ACD would be the same. The reason why beam 7 reaches higher shear capacity is not exactly clear from the view point of mechanics. However, this may be due to the interaction between concrete and ACD. Steel ACD may react on concrete more strongly than plastic one due to its higher stiffness. This results in higher
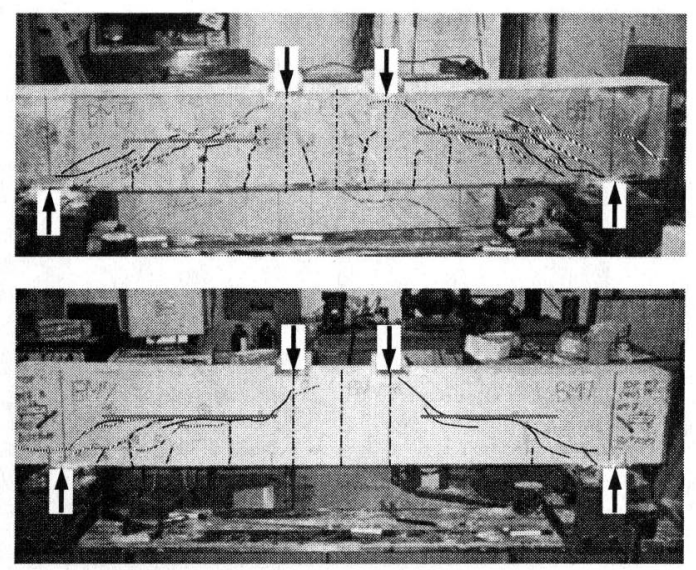

(a) Crack pattern showing numerous discontinuous diagonal cracks and crack diversion phenomenon

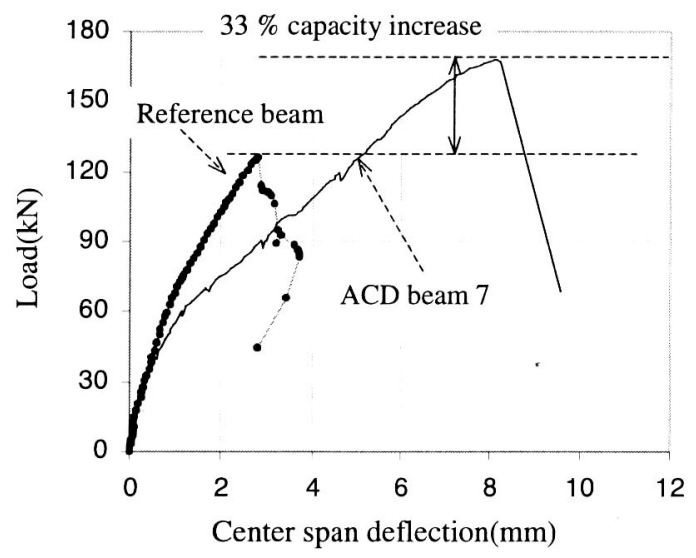

(b) Load-displacement relationship

Fig.28 Experimental result of beam 7

stress concentration and local damage in concrete, thus the failure may be more accelerated.

However, the effect of stiffness of material for ACD is not investigated in this study. In case that stiffness is zero, such as void or pre-crack penetrating the entire section, the interacting stresses applied on concrete would approach zero, thus the local damage may be small. Further investigation is needed to clarify this point.

However, it may be concluded that the strength of material for ACD does not affect the crack propagation behavior. The further investigation of ACD should therefore focus on non-metallic material from the viewpoint of long-term durability and easiness in manipulation.

\section{g) Beam 8}

In beam 8, two steel horizontal ACDs are embedded in each side of the beam. The crack pattern of beam 8 is shown in Fig.29a. Similar to beams 6 and 7, experimental observation shows that 

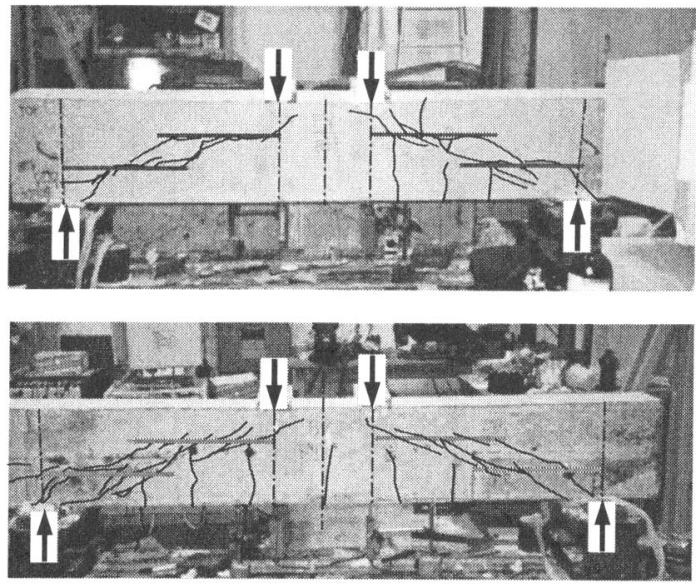

(a) Crack pattern

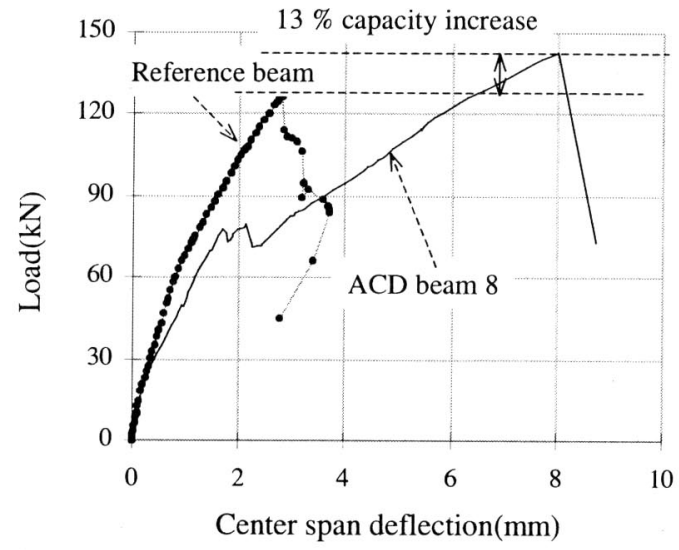

(b) Load-displacement relationship

Fig.29 Experimental result of beam 8

horizontal cracks along the interfaces of $\mathrm{ACD}$ appear firstly instead of the diagonal crack. Thus the crack arrest mechanism is shown. However, similar to beam 6 and beam 7, the drawback is still the premature horizontal crack at the ACD interface that noticeably degrades the stiffness.

The load-displacement relationship of this beam is shown in Fig.29b. As can be observed, loading capacity increases only $13 \%$. This is because, even if more ACD are used to achieve more effective crack arresting, this means that more weak locations are also provided to the beam. Thus, the failure path can also be readily formed as a result.

\section{CONCLUSIONS}

The paper proposes the control of crack localization through a device named artificial crack device (ACD). Based upon the experimental results, basic controls of crack localization, namely, specification of crack location, diversion of crack propagation, and crack arrest mechanism have been investigated in the experiment.

Through the crack arrest mechanism, a considerable increase in shear capacity up to more than $50 \%$ is found in the experiment without any stiffness degradation. The control is considered as alternative to reduce the excessive use of shear reinforcement. Moreover, the plastic ACD also shows good performance compared to the steel one. The use of non-metallic ACD may be more attractive from the viewpoint of long-term durability and the easiness in manipulation and fabrication.

Mechanically, ACD represents the local shear anisotropy, which differs from full sectional shear anisotropy of the pre-crack. Due to low shear transfer ability at ACD, the diagonal crack cannot propagate across, but the interface crack is resulted instead. Future research is to investigate the effect of stiffness of $A C D$ and the interaction between concrete and ACD contact.

The aim of the paper is to point out that the shear failure behavior can be significantly affected by ACD. This may lead to a new concept of control of crack localization behavior.

ACKNOWLEDGEMENT: This study was conducted with financial support by Grant-in-Aid for scientific research No. 12450174 from the ministry of Education, Science and Culture.

\section{REFERENCES}

1) Pimanmas, A. and Maekawa, K.: Influence of pre-crack on RC behavior in shear, Journal Materials, Conc. Struct., Pavements, JSCE, No.669/V-50, pp. 227-291, 2001.

2) Pimanmas, A. and Maekawa, K.: Finite element analysis and behavior of pre-cracked reinforced concrete member in shear, Accepted for publication in Mag.Conc.Res, Thomas Telford.

3) Pimanmas, A. and Maekawa, K.: Multi-directional fixed crack approach for highly anisotropic shear behavior in pre-cracked RC members, Journal Materials, Conc. Struct., Pavements, JSCE, No.669/V-50, pp. 293-307, 2001.

4) Okamura, H. and Higai, T.: Proposed design equation for shear strength of reinforced concrete beams without web reinforcement, Proc. of JSCE, Vol.300, pp. 131-141, 1980. 
人工亀裂を内在する $\mathrm{RC}$ 部材のひび割れ局所化と形成される破壊経路の制御

$$
\text { ピマンマス アモン・前川 宏一 }
$$

鉄筋によるせん断補強に過大に依存すると過密配筋となり,コンクリート施工上の問題を引き起こす. そのため,鉄筋コンクリート部材の総合的な品質の低下も危惧される. 必要にして十分なせん断補強鉄筋 を配置することが肝要である. 先行ひび割れを有する RC 梁の最近の実験から,ひび割れ相互干渉による分 散や進展停止が部材のせん断耐力を大きく上昇させる場合があることが確認された. この現象を逆手にと り,予め部材に埋め込まれた人工亀裂誘発材(ACD)によってひび割れ進展を制御する方法を,本研究で提案 するものである. 限定された条件ながら,実験検討を用いた人工亀裂によるひび割れ制御の可能性が示さ れた. 